Editorial

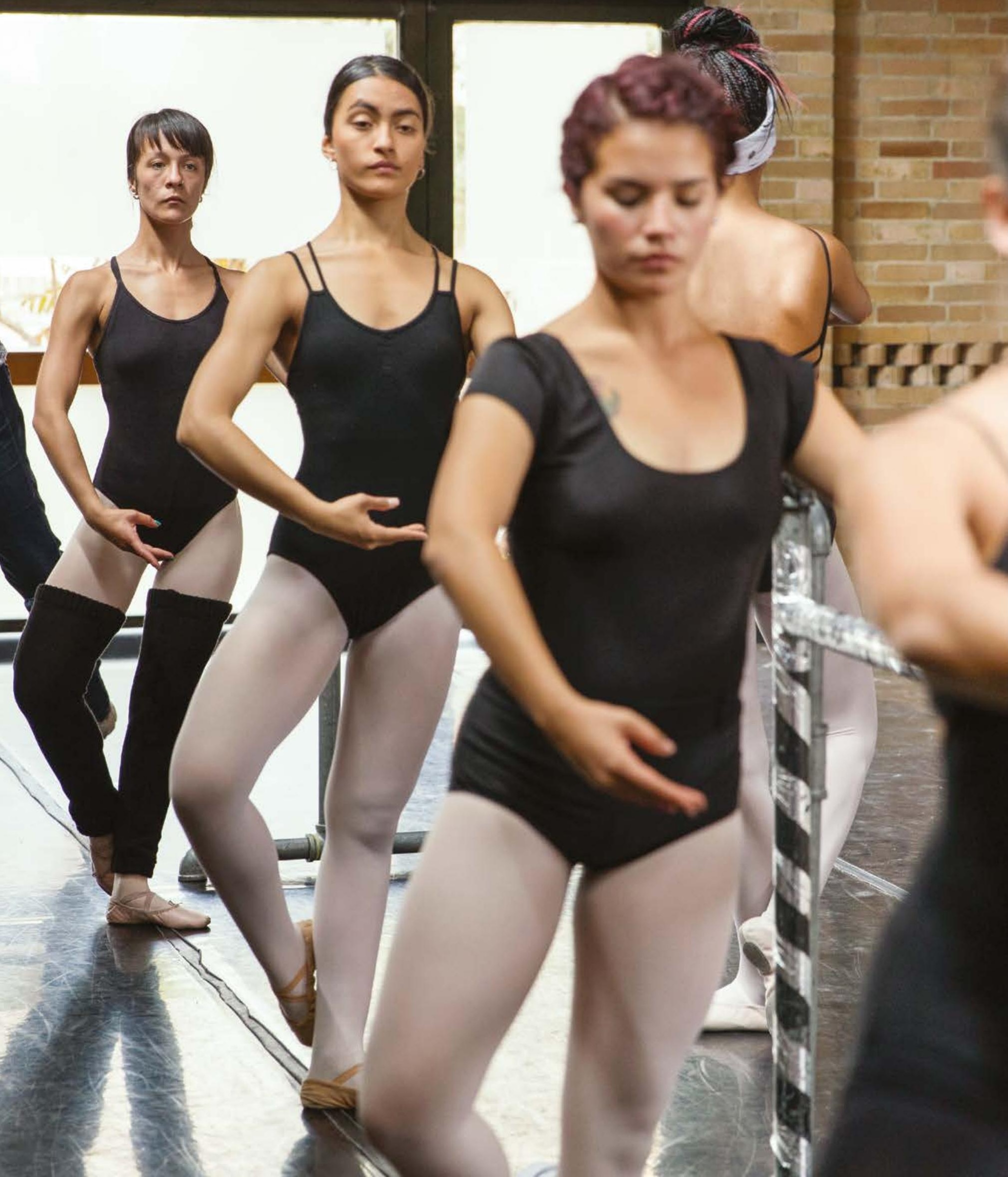




\section{Creación artística y creación aiestésica en la perspectiva de los estudios artísticos}

\author{
Pedro Pablo Gómez Moreno \\ Editor \\ Universidad Distrital Francisco José de Caldas, \\ Colombia \\ ppgmez@udistrital.edu.co
}

Cómo citar este artículo: Gómez Moreno, Pedro Pablo (2019). Creación artística y creación aiestésica en la perspectiva de los estudios artísticos. Estudios Artísticos: revista de investigación creadora, 5(6) pp. 14-16. DOI: https://doi. org/10.14483/25009311.14096

https://creativecommons.org/licenses/by/4.0/deed.es
Para los estudios artísticos, la creación artística es una forma legítima de conocer y pensar, que desde lo particular se constituye en determinante de lo universal. Es pensamiento en forma sensible, acumulado de sensaciones, que se articula por lógicas no necesariamente conceptuales y "lenguajes" simbólicos particulares que son el resultado de modos de hacer disruptivos que en su acontecer escapan a las regularidades, las regulaciones y las metodologías repetitivas. La creación artística da cuenta de los procesos históricos de las comunidades del denominado campo del arte, que se han ocupado de la construcción de un territorio propio de prácticas, experiencias sensibles, conceptuales y existenciales; un campo diferenciado respecto de otros campos constitutivos de la sociedad y la cultura, como la ciencia, la filosofía o la política. Además, debido al carácter no acumulativo del arte, cuyos despliegues no dejan obsoletos los agenciamientos anteriores ni formas otras de creación, -con sus respectivas poéticas, normativas y estéticas- la creación artística subsume una multiplicidad de procesos que actualizan permanentemente los modos de hacer, la elaboración objetual y la creación de significantes y significados; todos ellos como mediaciones para la proyección de horizontes otros de sentido para la existencia humana.

Ahora bien, quizá se podría decir que la creación artística es al arte lo que la investigación científica a las ciencias. Esta especie de pertenencia categorial a un determinado campo puede ser útil si se trata de establecer especificidades, territorios y dominios. Tal diferenciación es posible desde una perspectiva habermasiana que tiene una particular concepción de la modernidad cultural como "la separación de la razón sustantiva, expresada en la 
religión y la metafísica, en tres esferas autónomas: ciencia, moralidad y arte, que se diferenciaron porque las visiones del mundo unificadas de la religión y la metafísica se escindieron" (Habermas, 1989, pp. 137-138). Sin embargo, sabemos que, en el despliegue de las esferas de la modernidad, el arte -en tanto modo de conocimiento sensible- quedó subordinado a la ciencia como conocimiento racional y a su vez, el arte, como poiesis especial, subordinó la poiesis general estableciendo barreras con respecto a la artesanía y a la producción mecánica industrial. Esa diferenciación y jerarquización es parte de la historia del poder, del accionar de su matriz colonial instalada en América en el siglo XVI (Quijano, 2000, p. 345). De ahí, la necesidad de descolonización del conocimiento en todas sus dimensiones, entre ellas, la creación artística para que no quede acotada a la noción occidental de arte.

En consecuencia, los estudios artísticos, para ser consecuentes con su perspectiva crítica y decoIonial, deberán pensar tanto en las condiciones de posibilidad de ampliación del horizonte de la creación más allá del arte, como en la desjerarquización de las formas de creación de conocimientos. Así, uno de los retos consiste en ampliar el reconocimiento de la capacidad creadora de los seres humanos, más allá de los campos de la ciencia y el arte. Ese despliegue se podría lograr mediante el diálogo entre artistas, científicos, creadores artesanos y creadores industriales y no sería otra cosa que la instauración del espacio ampliado de la investigación-creación. Para tal fin, se debe tener en cuenta que la matriz colonial del poder opera en la modernidad reproduciéndose espacial y temporalmente en una serie de heterarquías. En esa serie la ciencia es colonizada históricamente por el poder imperial, el poder estatal y finalmente, por el poder empresarial y el neoliberalismo económico. A su vez, el conocimiento científico, como capacidad creadora de la ciencia, coloniza al arte-como subordinación de la estética a la epistemología, de la poiesis a la objetividad, del sentimiento a la razón-facilitando su control por parte del poder; dicho de otro modo, la creación científica (en tanto investigación) coloniza a la creación artística (como creación no-científica). En un siguiente nivel, el arte coloniza las artesanías, (o en su diferenciación las constituye como tales) como los haceres y sentires no-artísticos que se realizan en el campo de la cultura no-letrada, en la "ciudad real", para decirlo en términos de Ángel Rama (1998). El arte coloniza a la artesanía como subordinación del hacer repetitivo al hacer original, auspiciado por la estética, reducida esta a filosofía del arte moderno occidental. Pero, sobre todo no hay que olvidar que ese despliegue de la matriz colonial del poder implica, al mismo tiempo, la clasificación social y jerarquización de las personas que ejercen cada una de las mencionadas actividades, en una operación en la que la división internacional del trabajo se complementa con la colonialidad del conocimiento, del ser y el sentir, la subjetividad, la autoridad y la colonialidad de la naturaleza.

Un buen número de los artículos que publicamos en Estudios Artísticos: revista de investigación creadora, están empeñados en abordar y profundizar estas problemáticas que aquí apenas hemos esbozado. Y la emergencia de esa comunidad de sentido no podemos hacer más que celebrarla.

\section{Referencias}

Gómez, P.P. (2017). La investigación-creadora o el horizonte ampliado de la investigación-creación. Estudios Artísticos: revista de investigación creadora. 3(3), pp. 8-11. doi: https://doi. org/10.14483/25009311.12525

(2015). Investigación y artes creadoras: la ruta de un senti-pensar otro posible. Estudios Artísticos: revista de investigación creadora, 1(1), pp. 8-13. doi: https://doi. org/10.14483/25009311.10245

Habermas, J. (1989). Modernidad un proyecto incompleto. En N. Casullo (Ed.), Casullo, Nicolás. Buenos Aires: Punto Sur Editores.

Quijano, A. (2000). Colonialidad del poder y clasificación social. Journal of World-systems research, VI, 2, pp. 342-386. Rama, A. (1984). La ciudad letrada. Montevideo, Uruguay: Comisión Uruguaya pro Fundación Internacional Ángel Rama. 